\title{
Conhecimento, Acurácia Diagnóstica e Esforço Mental Durante Resolução de Caso Clínico por Estudantes de Medicina
}

\section{Relationship Between Knowledge, Diagnostic Accuracy and Mental Effort During Clinical Case Resolution by Medical Students}

\author{
Gabriela Araujo Costa ${ }^{1}$ \\ Cassio da Cunha Ibiapina ${ }^{2}$ \\ Marcos Xavier Silva ${ }^{3}$ \\ Maria Clara Argolo Costa ${ }^{4}$ \\ Beatriz Mota Tiburcio ${ }^{5}$ \\ Lucas Lisboa Torquette ${ }^{6}$ \\ Isabella Valadares Cesar Evangelista ${ }^{7}$
}

\section{RESUMO}

Objetivo: Este trabalho objetiva descrever a relação entre a acurácia diagnóstica, o esforço mental e a percepção de conhecimento prévio em uma amostra de estudantes de medicina expostos a casos clínicos de pneumonia. Metodologia: Sessenta e um alunos de medicina do quarto ano analisaram casos clínicos de pneumonia (bacteriana, com derrame pleural e viral) e determinaram o diagnóstico provável, o grau de esforço mental para esta tarefa e o grau de conhecimento prévio dessas patologias. A relação entre estas variáveis foi avaliada por estudo de correlação de Pearson e análise de componentes principais. Resultados: Um terço dos estudantes diagnosticou corretamente os casos de pneumonia bacteriana e viral e apenas $10 \%$ deles diagnosticou corretamente pneumonia com derrame pleural. Os alunos relataram menor conhecimento prévio e maior percepção de esforço mental na resolução deste caso. A relação entre a acurácia e o esforço mental foi inversa e estatisticamente significativa apenas para o caso de pneumonia viral $(r:-0,3503, p=0,0056)$. Em todos os casos ocorreu associação significativa e inversamente proporcional entre o conhecimento prévio e o esforço mental. Conclusão: A relação entre maior percepção de conhecimento prévio sobre a doença, maior acurácia diagnóstica e menor esforço mental não foi observada neste estudo. É necessário o estímulo de pesquisas que aprimorem os processos envolvidos na mobilização de recursos cognitivos para realização de diagnósticos corretos, potencializando estratégias de ensino que culminem em melhor acurácia diagnóstica com menor grau de esforço mental.

\section{DESCRITORES}

Educação Médica. Bases de Conhecimento. Metacognição. Autoavaliação Diagnóstica.

\begin{abstract}
Objective: This work aims to describe the relationship between diagnostic accuracy, mental effort and perception of previous knowledge in a sample of medical students exposed to clinical cases of pneumonia. Methodology: Sixty-one fourth-year medical students analyzed clinical cases of pneumonia (bacterial, with pleural and viral effusion) and determined probable diagnosis, degree of mental effort for this task and degree of prior knowledge of these pathologies. The relationship between these variables was assessed by a Pearson correlation study and Principal Component Analysis. Results: One third of the students correctly diagnosed cases of bacterial and viral pneumonia, only $10 \%$ of them correctly diagnosed pneumonia with pleural effusion. The students reported less prior knowledge and greater perception of mental effort in solving this case. The relationship between accuracy and mental effort was inverse and statistically significant only for the case of viral pneumonia ( $r:-0.3503, p=0.0056$ ). In all cases there was a significant and inversely proportional association between prior knowledge and mental effort. Conclusion: The relationship between greater perception of prior knowledge about the disease, greater diagnostic accuracy and less mental effort was not observed in this study. It is necessary to stimulate research that improves the processes involved in the mobilization of cognitive resources to carry out correct diagnoses, enhancing teaching strategies that culminate in better diagnostic accuracy with a lower degree of mental effort.
\end{abstract}

DESCRIPTORS

Medical Education. Knowledge Bases. Metacognition. Self-Assessment.

${ }^{1}$ Mestre em Clínica Médica e Biomedicina, Médica Pediatra na Prefeitura Municipal de Belo Horizonte e Professora do Núcleo de Pediatria da Faculdade de Medicina do Centro Universitário de Belo Horizonte (UniBH), Belo Horizonte, MG, Brasil.

${ }^{2}$ Pós-Doutorado em Educação Médica, Professor Associado III no Departamento de Pediatria da Faculdade de Medicina da Universidade Federal de Minas Gerais, Belo Horizonte, MG, Brasil.

${ }^{3}$ Doutor em Saúde Animal com ênfase em Epidemiologia, Professor Adjunto no Departamento de Medicina Veterinária Preventiva da Escola de Veterinária da Universidade Federal de Minas Gerais, Belo Horizonte, MG, Brasil.

${ }^{4}$ Médica generalista da Unidade de Pronto Atendimento Barreiro, Prefeitura Municipal de Belo Horizonte, Belo Horizonte, MG, Brasil.

${ }^{5}$ Residente em Clínica Médica no Hospital Madre Tereza, Belo Horizonte, Belo Horizonte, MG, Brasil.

${ }^{6}$ Médico generalista da atenção primária, Prefeitura Municipal de Belo Horizonte, Belo Horizonte, MG, Brasil.

${ }^{7}$ Acadêmica de Medicina do $12^{\circ}$ período, Faculdade de Medicina do Centro Universitário de Belo Horizonte (UniBH), Belo Horizonte, MG, Brasil. 
U $\mathrm{m}$ dos principais determinantes da qualidade da assistência prestada ao paciente é a competência diagnóstica, definida como a capacidade de mobilizar recursos cognitivos para, a partir da história clínica, definir o diagnóstico mais provável e propor o tratamento adequado ao mesmo ${ }^{1}$. A competência diagnóstica é formada por vários atributos, entre os quais a acurácia, que é a precisão na definição correta do quadro clínico de um paciente. Diagnósticos incorretos podem ocorrer em até $15 \%$ dos atendimentos e o principal fator determinante são os lapsos na forma de organização e utilização do conhecimento pelo profissional, durante a abordagem ao paciente ${ }^{2}$. Tais erros podem levar a decisões e condutas médicas equivocadas, com resultados clínicos indesejáveis, tanto do ponto de vista clínico quanto financeiro e socioemocional|3 ${ }^{3,4}$. Por isso, identificar fatores associados ao desenvolvimento da habilidade precisa de raciocínio clínico tem sido foco de atenção de pesquisadores em educação médica ${ }^{5,6}$. Embora haja um crescente número de trabalhos nessa linha de pesquisa, inúmeras questões permanecem ainda sem resposta, especialmente aquelas ligadas à compreensão dos processos cognitivos envolvidos no desenvolvimento do raciocínio clínico ${ }^{7}$. O conhecimento sobre ferramentas e estratégias que facilitem a aquisição de atributos para alcançar a competência diagnóstica torna-se de vital importância para qualificar a formação profissional ${ }^{8-9}$.

O modelo de educação médica formal é caracterizado pelo raciocínio analítico durante as fases iniciais do curso, nas quais o aluno adquire conhecimentos sobre os mecanismos fisiopatológicos e biológicos das doenças, baseado em um modelo que explique as causas e consequências de cada uma das manifestações clínicas apresentadas por um paciente. Quando se inicia a prática clínica, o aluno soma ao conhecimento teórico a experiência adquirida durante os atendimentos e forma "scripts mentais", modelos simplificados de doenças similares aos quadros teóricos estudados em sua formação inicial, que são arquivados na memória ${ }^{10}$. À medida que é exposto a maior número de pacientes e a casos mais complexos, o aluno percebe que uma mesma doença pode apresentar-se de formas diferentes do padrão arquivado, exercitando o raciocínio reflexivo reorganizando novos modelos mentais, que contemplam as variações clínicas de uma mesma doença e a possibilidade de um grupo particular de sinais e sintomas relacionar-se a uma ou mais doenças ${ }^{11,12}$. Durante esse processo, vários fatores podem influenciar a aquisição da acurácia diagnóstica, tais como as percepções de reconhecimento prévio do conteúdo exposto e de esforço mental despendido para a resolução de um caso clínico. A precisão destes julgamentos de monitoramento pode influenciar na habilidade de raciocinar clinicamente e, por isso, todos esses fatores devem ser estudados como importantes ferramentas a serem manejadas por professores e alunos, na busca da acurácia e, consequentemente, da competência diagnóstica ${ }^{13,14}$. O objetivo desse artigo foi descrever a relação entre a acurácia diagnóstica, o grau de esforço mental e a percepção de conhecimento prévio em uma amostra de estudantes de medicina do quarto ano, expostos a casos clínicos simples e complexos de pneumonia. 


\section{METODOLOGIA}

Estudo experimental realizado com alunos de medicina de uma faculdade privada de Belo Horizonte. O público alvo foi constituído de alunos do quarto ano porque nesse período do curso os participantes já teriam sido expostos a conteúdo teórico sobre as patologias que compõem os casos clínicos, mas teriam pouca experiência prática com as mesmas, reduzindo o efeito de expertise reversa ${ }^{1}$.

O cálculo amostral realizado para garantir a representatividade da amostra ( $n=151$ ), com um nível de confiança de $90 \%$ foi de 67 participantes. Os dados foram coletados entre março e novembro de 2018.

$\mathrm{Na}$ etapa inicial do estudo, cada estudante assinou o termo de consentimento livre e esclarecido e recebeu uma lista de doenças, dentre as quais constavam as patologias do trato respiratório cuja acurácia seria avaliada na pesquisa. Na lista, o participante deveria determinar o seu grau de conhecimento com cada patologia. Esta variável foi medida utilizando-se uma escala Likert, variando de um a cinco, conforme o grau de conhecimento teórico com cada doença ( 1 - nulo, 2 - muito limitado; 3 -razoável; 4 -bom; 5 - excelente). Para a análise dos resultados, foi calculada a taxa média de conhecimento prévio, pelo somatório dos escores da amostra marcados na escala Likert do instrumento próprio para essa avaliação.

Paralelamente, foi verificado na matriz curricular do curso quantas vezes o conteúdo associado à pneumonia foi apresentado aos estudantes nos semestres anteriores, nas disciplinas comuns e obrigatórias do currículo, tais como semiologia, patologia clínica, entre outras, e quais alunos haviam cursado a disciplina optativa de pneumologia.

Em um segundo momento, o participante recebeu um bloco de 12 casos clínicos escritos, dentre os quais estavam àqueles relacionados às patologias cuja acurácia se desejava determinar no estudo (pneumonia viral e bacteriana - casos simples e com derrame pleural - caso complexo). Os casos cuja acurácia não seria mensurada envolviam doenças diversificadas e sua função era apenas compor o bloco e evitar que os participantes percebessem em quais teriam seu desempenho diagnóstico medido. Cada caso era estruturado com anamnese, exame físico e exames complementares (Figura 1) e era baseado em casos reais atendidos pelos pesquisadores. Antes de serem aplicados aos alunos foram avaliados por dois pediatras experientes, professores da faculdade $\mathrm{e}$ não pertencentes ao estudo. Foi destinado o tempo de um minuto e meio para a resolução de cada caso, mesmo período utilizado em trabalhos anteriores conduzidos com a mesma metodologia ${ }^{5,15,16}$. Ao término deste tempo, os alunos deveriam fornecer diagnóstico da forma mais precisa que pudessem e marcar o grau de esforço mental utilizado na resolução.

Para a análise do grau de acurácia diagnóstica, foi considerado o diagnóstico que o aluno tinha registrado como sendo o mais provável após a leitura do caso. Toda a variedade de diagnósticos fornecidos pelos participantes foi transcrita para uma lista e cada um foi pontuado em 0,$0 ; 0,5$ ou 1,0 , com as respectivas correspondências: 0,0 , diagnóstico absolutamente incorreto (exemplo: gripe); 0,5 diagnóstico sindrômi- 
co (exemplo: pneumonia); 1,0 diagnóstico absolutamente correto (exemplo: pneumonia viral). As pontuações foram inicialmente dadas por dois pediatras, professores com mais de 25 anos de experiência clínica. Cada um desses profissionais desconhecia as notas dadas pelo outro. O nível de concordância (Coeficiente de Kappa) entre as notas dadas pelos dois avaliadores foi superior a $98 \%$. Nos casos de discordância, um terceiro pediatra, também professor, com mais de 40 anos de experiência fazia a pontuação das respostas e a nota final era aquela coincidente em duas avaliações.

Para o registro de esforço mental cada participante assinalou, em uma escala visual de 1 até 9 , o grau de esforço que considerasse que the tinha sido exigido para a solução do caso, sendo 1 o esforço "muito muito baixo" e 9 esforço "muito muito alto" (Figura 1). Esta escala foi adaptada do Índice de Carga de Tarefa da NASA (TLX) e validada em estudos anteriores que utilizaram metodologia semelhante à deste trabalho ${ }^{5,15-17}$. Para a análise dos resultados foi calculada a taxa média de esforço mental da amostra, pelo somatório dos escores marcados na escala visual própria para essa avaliação.

Foram analisadas então as variáveis acurácia diagnóstica, esforço mental e conhecimento prévio e a relação pareada entre elas. As análises estatísticas de comparação de correlações pareadas foram realizadas utilizando o estudo de correlação de Pearson, com o Programa Stata 12.0. Para isso, foi realizada uma matriz de correlação dos dados com a utilização de um valor de $(p)$ menor ou igual a 0,05 , com critério de distinção estatisticamente significativa. Para a análise multivariada, foi realizada a análise de componentes principais, gerando um resultado cuja interpretação múltipla traz ao estudo uma maior dinâmica de análise.

A pesquisa foi aprovada pelo comitê de ética local, cadastrado no CAAE sob número 81421917.7.0000.5149 (23/02/2018), tendo recebido apoio financiamento dos próprios autores e de uma bolsa de pesquisa emitida

Figura 1. Modelo de caso clínico estruturado utilizado no trabalho
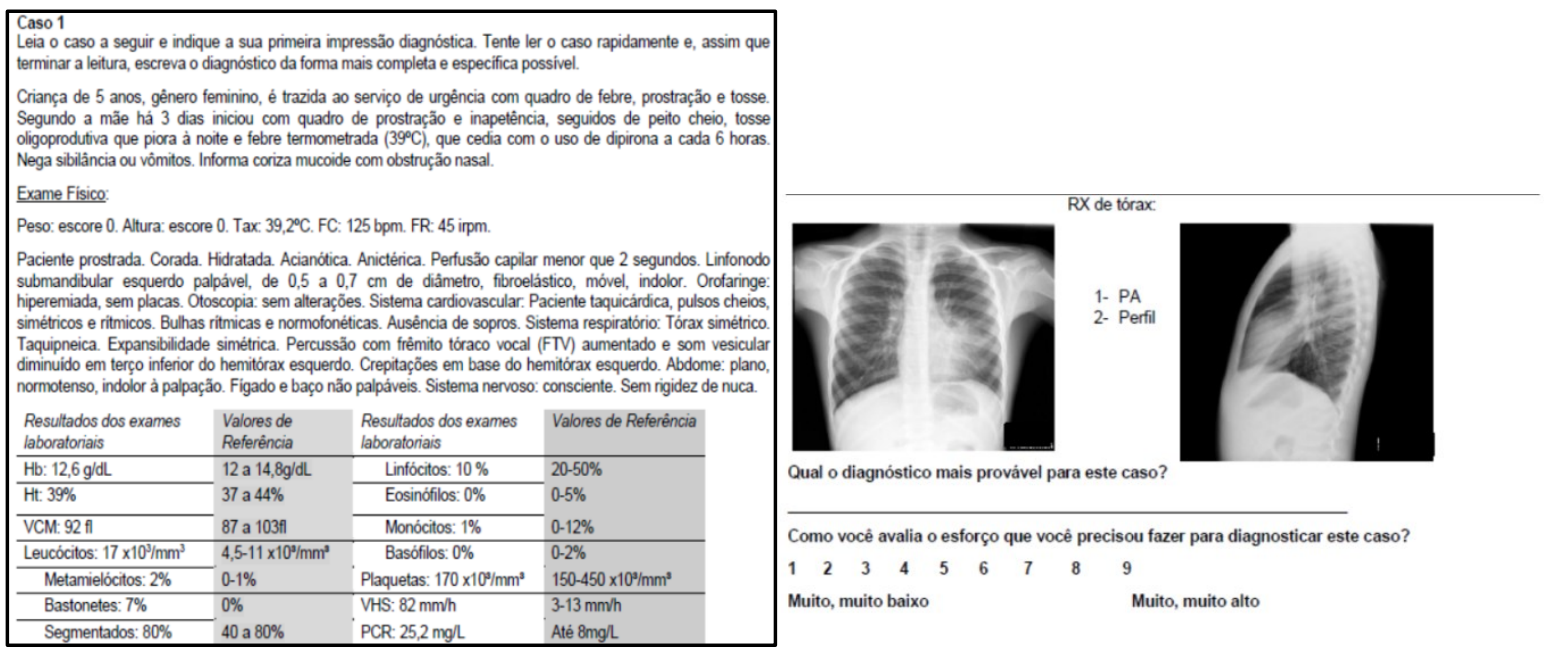
pelo Centro Universitário de Belo Horizonte, para a pesquisadora principal, no período de março de 2018 a março de 2019.

\section{RESULTADOS}

Dos 151 alunos matriculados no quarto ano do curso, no ano de 2018, 68 concordaram em participar do estudo ( $45 \%$ do público alvo). Após a aplicação do bloco de casos clínicos, sete alunos foram excluídos, pois não escreveram nenhum diagnóstico em um ou mais dos casos de pneumonia avaliados. Foram então avaliados 61 alunos. Destes, $75 \%$ eram mulheres (mesma distribuição por sexo que a amostra inicial -73,5\%) e 18 $(29,5 \%)$ fizeram a disciplina optativa de Pneumologia antes da participação na pesquisa. A idade média da amostra foi de 25 anos.

As análises estatísticas de comparação de correlações pareadas mostraram que os resultados apresentaram uma forte corre- lação em função de um pareamento realizado com amostragem suficiente $(n=61)$.

A Tabela 1 mostra a porcentagem de alunos que acertaram o diagnóstico em cada caso clínico (denominada como acurácia diagnóstica), as médias de escore do esforço mental para a resolução do caso e do grau de conhecimento teórico prévio da patologia a qual o caso clínico se relacionava.

A maior taxa de acerto foi para o caso 1 (pneumonia bacteriana), cujo diagnóstico foi realizado corretamente por 20 estudantes. Para a patologia considerada de maior complexidade (pneumonia com derrame pleural) observou-se que a taxa de acerto foi menor que $10 \%$; os alunos relataram menor conhecimento prévio desta doença e maior percepção de esforço mental para a resolução deste caso.

Para o caso 1 (pneumonia bacteriana), 17 dos 20 estudantes que apresentaram elevada acurácia diagnóstica (pontuação 1

Tabela 1. Valores de acurácia diagnóstica e médias de escore de esforço mental e de conhecimento prévio da doença para cada caso clínico

\begin{tabular}{|c|c|c|c|}
\hline Caso clínico & $\begin{array}{c}\text { Acurácia } \\
\text { Diagnóstica } \\
\text { n } \quad \%\end{array}$ & $\begin{array}{c}\text { Esforço } \\
\text { Mental ** } \\
\text { (média 1-9) }\end{array}$ & $\begin{array}{l}\text { Conhecimento prévio } * * * \\
\text { (média } 1-5)\end{array}$ \\
\hline $\begin{array}{l}\text { Caso } 1 \\
\text { Pneumonia } \\
\text { bacteriana }\end{array}$ & $20 \quad 32,8$ & 5,6 & 3,6 \\
\hline $\begin{array}{l}\text { Caso } 2 \\
\text { Pneumonia } \\
\text { com derrame }\end{array}$ & $04 \quad 6,55$ & 7,0 & 2,7 \\
\hline $\begin{array}{l}\text { Caso } 3 \\
\text { Pneumonia } \\
\text { viral }\end{array}$ & $16 \quad 26,2$ & 6,8 & 3,3 \\
\hline
\end{tabular}

* Considerada como pontuação 1,0 - diagnóstico absolutamente correto

** Escala visual que variou de 1 (mínimo esforço mental) a 9 (máximo esforço mental)

*** Escala Likert que variou de 1 (conhecimento prévio nulo) a 5 (conhecimento prévio excelente)

Fonte: dados dos autores 
- diagnóstico correto e claramente descrito) relataram que o seu esforço mental para fazer o diagnóstico foi baixo (escores 1-2 - "muito baixo" ou "muito muito baixo"). Dos 20 estudantes que acertaram o diagnóstico, mais de $60 \%$ avaliaram a sua percepção do conhecimento sobre pneumonia bacteriana como "muito limitada" (escore 2 na escala Likert).

No caso 2 (pneumonia com derrame), $64 \%$ dos estudantes conseguiram diagnosticar o processo pneumônico, mas não o derrame, que foi diagnosticado por apenas quatro dos 61 participantes do estudo. Para a resolução deste caso, $65 \%$ dos alunos consideraram ser necessário um alto grau de esforço mental (escores 7-9 na escala visual de esforço mental) e $42 \%$ avaliaram o conhecimento prévio sobre a doença como "nulo" ou "muito limitado".

Ao mensurar-se a acurácia diagnóstica para o caso 3 (pneumonia viral), um quarto dos participantes definiu corretamente o diagnóstico e $37 \%$ conseguiram identificar a infecção como localizada nas vias aéreas inferiores, mas não conseguiram identificar corretamen- te a etiologia viral. Para este caso, $70 \%$ dos participantes avaliou o esforço mental para se chegar ao diagnóstico como alto (escores 7-9 na escala visual), embora mais de $80 \%$ tenha referido o conhecimento prévio sobre esta patologia como "razoável" a "excelente" (escores 3-5 na escala Likert).

Foram encontradas correlações estatisticamente significativas entre o conhecimento prévio e o esforço mental em todos os casos (pneumonia bacteriana; $p=0,0047$, pneumonia com derrame; $p=0,0065$ e pneumonia viral; $p=0,0004)$. Nesta análise pareada, o valor de coeficiente de correlação de Pearson mostrou que o conhecimento prévio da doença está inversamente relacionado à percepção de esforço mental despendido para a resolução do caso clínico sobre a referida doença (Tabela 2).

A relação entre a acurácia e o esforço mental foi estatisticamente significativa apenas para o caso 3 (pneumonia viral), no qual foi observada relação inversa entre estas variáveis $(r:-0,3503 ; p=0,0056)$.

Tabela 2. Análise pareada entre conhecimento prévio $(C)$ da doença e esforço mental (EM) para a resolução do caso clínico da referida doença

\begin{tabular}{l|c|c|c}
\hline \multicolumn{1}{c|}{ Caso } & Comparação & $\begin{array}{l}\text { Coeficiente de } \\
\text { Correlação de } \\
\text { Pearson (r) }\end{array}$ & Valor de p \\
\hline $\begin{array}{l}\text { Caso 1 } \\
\begin{array}{l}\text { Pneumonia } \\
\text { bacteriana }\end{array}\end{array}$ & C1 x EM1 & $-0,3574$ & 0,0047 \\
\hline $\begin{array}{l}\text { Caso 2 } \\
\begin{array}{l}\text { Pneumonia } \\
\text { com derrame }\end{array}\end{array}$ & C2 x EM2 & $-0,2578$ & 0,0065 \\
\hline $\begin{array}{l}\text { Caso 3 } \\
\text { Pneumonia } \\
\text { viral }\end{array}$ & C3 EM3 EM & $-0,4397$ & 0,0004 \\
\hline
\end{tabular}

Fonte: dados dos autores 
Figura 2. Mapa fatorial para análise de correspondência das variáveis acurácia diagnóstica (a), conhecimento prévio (c) e esforço mental (em), para cada caso clínico (1 - pneumonia bacteriana; 2 - pneumonia viral; 3 - pneumonia com derrame pleural)

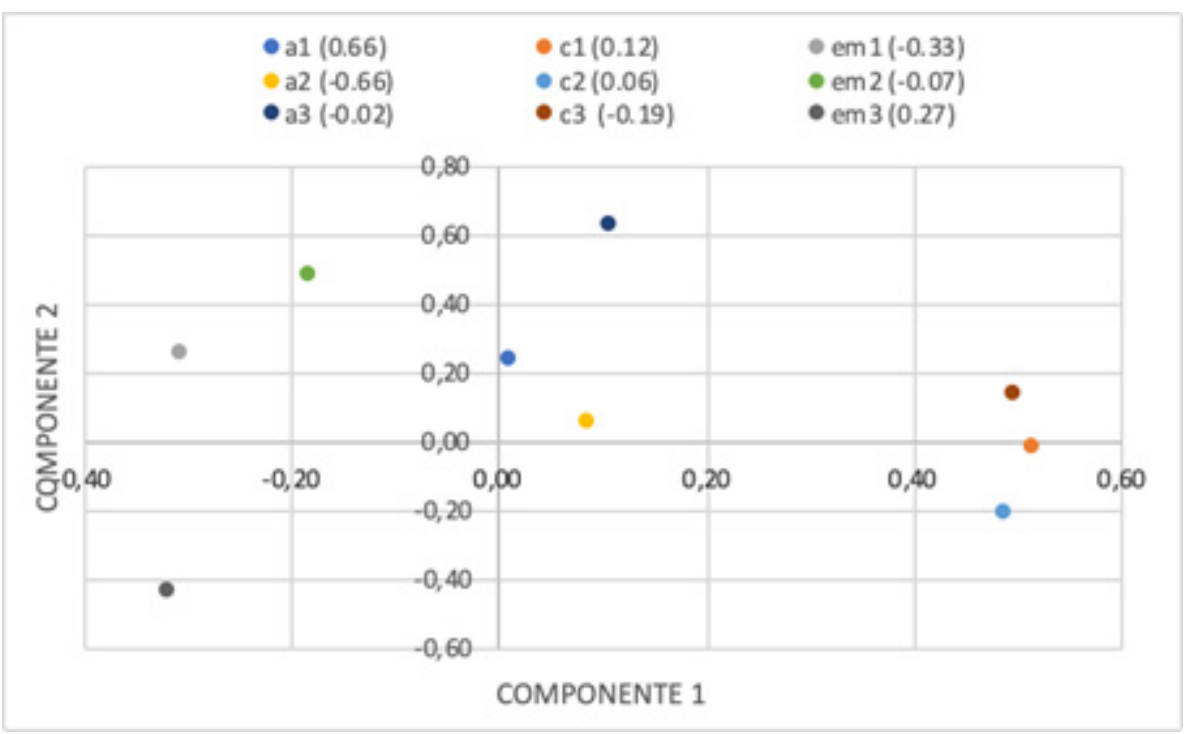

Legenda: a - acurácia; c- conhecimento prévio; em - esforço mentalFonte: dados dos autores

A análise multivariada foi realizada por meio da análise de componentes principais (ACP). Foi possível mensurar $58,24 \%$ das variações totais possíveis de serem identificadas entre as respostas avaliadas neste estudo, percentual considerado muito bom ${ }^{18}$. A ACP confirmou os achados da análise pareada. $O$ agrupamento em proximidade das variáveis do grupo acurácia e do grupo conhecimento prévio (Figura 2) identificou estes dois grupos com maior correlação nos casos 1, 2 e 3. As variáveis do grupo esforço mental, por sua vez, foram as que apresentaram maior dispersão espacial, mostrando menor correlação entre os casos 1, 2 e 3.

Nos semestres anteriores ao estudo, os alunos tinham sido homogeneamente expostos a conhecimentos teóricos associados aos diferentes tipos de pneumonia avaliados neste trabalho em oito diferentes disciplinas (Anatomia, Histologia, Anatomia Patológica, Patologia Clínica, Semiologia 1 e 2, Clínica Médica 1 e Pediatria 1). A participação prévia em disciplina optativa de Pneumologia não teve impacto na acurácia diagnóstica (caso 1; $p=0,9716$; caso $2 ; p=0,7728$ e caso 3 ; $p=0,576)$.

\section{DISCUSSÃO}

O automonitoramento do aprendizado auxilia o estudante a saber quando utilizar estratégias de raciocínio analítico e não analítico e a regular sua aprendizagem, identificando padrões já conhecidos de doença e o esforço mental que precisa realizar para resolver um caso clínico, fatores que podem auxiliá-lo na definição correta do diagnóstico ${ }^{13,14}$. Neste 
estudo, no qual foi avaliada a relação entre a autopercepção de conhecimento prévio, de esforço mental e de acurácia durante a resolução de casos de pneumonia, ocorreu uma associação significativa entre o conhecimento prévio e o esforço mental, isto é, quanto maior o conhecimento prévio autorelatado da doença, menor a percepção de esforço mental para reconhecê-la em um caso clínico estruturado, embora essa relação não tenha necessariamente determinado maior acurácia diagnóstica.

A associação entre o conhecimento prévio e o esforço mental pode ser justificada pela exposição repetida ao conteúdo "pneumonia", colaborando para a criação de modelos mentais ou scripts de doenças que ficam armazenados na memória em longo prazo. Quando é exposto ao aluno um caso semelhante ao que já estudou (como, por exemplo, pneumonia bacteriana), o script da doença é ativado, diminuindo o esforço mental para elaborar o diagnóstico correto ${ }^{19}$. Entretanto, neste estudo, a exposição repetida a conteúdos relacionados à pneumonia durante a graduação dos estudantes do quarto ano do curso de medicina não se correlacionou à autopercepção do conhecimento elevado, conforme o esperado ${ }^{20}$. O conteúdo relacionado à pneumonia, suas etiologias e complicações já tinha sido apresentado aos participantes do estudo, até o momento do experimento, em oito disciplinas diferentes, no ciclo básico (como histologia e fisiologia) e no ciclo de formação de habilidades, com atendimento prático (como em semiologia, clínica médica e pediatria). Esperava-se que, para as patologias cujos casos clínicos foram apresentados para resolução, quanto maior a percepção do grau de conhecimento prévio sobre a doença, maior seria a acurácia diagnóstica e menor o grau de esforço mental para se chegar ao diagnóstico correto. A baixa autopercepção de conhecimento prévio do conteúdo relacionado à pneumonia pode estar associada à baixa acurácia diagnóstica, na medida em que, ao não reconhecer a exposição repetida a este conteúdo, muitas vezes exposto de forma fragmentada e não estruturada, ao longo da graduação, o aluno não consegue agrupar conhecimentos fisiopatológicos e clínicos, que o auxiliarão no encapsulamento de conhecimentos culminando na formação de scripts mentais ${ }^{1}$. Este achado é de extrema relevância, visto que o conhecimento médico e a habilidade de elaborar hipóteses diagnósticas a partir de dados clínicos foram considerados por vários autores como duas das mais importantes características para um aluno possuir ou adquirir na preparação para a prática geral ${ }^{21,22}$.

Para o caso "pneumonia bacteriana", no qual foi observada a maior taxa de acurácia entre as patologias apresentadas, ocorreu uma correlação positiva entre maior acurácia e menor esforço mental (embora não estatisticamente significativa). Para os casos de pneumonia viral e pneumonia com derrame, a maioria dos alunos teve dificuldade em diagnosticar corretamente a etiologia do processo infeccioso ou a complicação, também relatando alto grau de esforço mental para a resolução destes casos. Estudo alemão desenvolvido com estudantes de medicina no quarto e quinto ano de uma faculdade, expostos a representações clínicas de quatro casos clínicos, mostrou que os déficits dos estudantes no diagnóstico são mais prováveis devido 
a lacunas de conhecimento, especialmente 0 fisiopatológico ${ }^{23}$. Mamede e colaboradores ${ }^{24,25}$ encontraram resultados semelhantes, observando que o conhecimento e a experiência clínica limitados, em alunos de graduação, os levavam a utilizar o raciocínio analítico na resolução de casos estruturados, mas que tal estratégia não melhorou as decisões sobre problemas complexos nem os ajudou a superar a influência de características semiológicas de distração presentes nos casos.

Um estudo com 52 alunos holandeses do segundo e sexto ano de medicina analisou os efeitos dos conhecimentos dos alunos, da complexidade de casos clínicos e sua interação com a acurácia diagnóstica e o esforço mental e mostrou que, dentre as variáveis analisadas, apenas o conhecimento prévio da doença a qual o caso se relacionava foi um fator significativo $(p<0,001)$ e correlacionou-se positivamente com a acurácia diagnóstica, tanto em casos simples $(p<0,001)$ quanto complexos $(p=0,002)$. Para o resultado da acurácia diagnóstica, nem a complexidade do caso $(p=0,42)$, nem a interação entre a complexidade do caso e o conhecimento ( $p$ $=0,64)$ tiveram efeito. Neste estudo, foi observado que o maior esforço mental esteve associado com uma menor acurácia diagnóstica $(p=0,001)^{20}$. Acredita-se que variáveis que aumentem a proporção de crenças falso positivas sobre a possibilidade de estar correto em seu diagnóstico, tais como características de distração salientes no caso clínico ou viés de disponibilidade, possam desencadear excesso de confiança, induzindo à distração da reflexão e dificultando a ativação do processamento analítico, levando o aluno a aceitar o primeiro diagnóstico que lhe venha à mente como correto e não contrapor diagnósticos diferenciais possíveis que o levem a refletir sobre a possibilidade do primeiro diagnóstico estar equivocado ${ }^{26}$.

Para o derrame pleural, a baixa acurácia diagnóstica encontrada neste estudo pode resultar da autopercepção de conhecimento prévio dos estudantes sobre a patologia como nula ou muito limitada, devido a lacunas no conhecimento prévio por pouca exposição ao conteúdo estruturado sobre o tema, contribuindo para uma baixa taxa de encapsulamento e formação de scripts mentais da doença pelos alunos $^{27}$. Outra hipótese a ser aventada seria a necessidade de funcionamento do sistema analítico, por tratar-se de caso mais complexo, para o qual seria necessário mais tempo para selecionar hipóteses e avaliá-las, o que não era compatível com o desenho do estudo, no qual estava previsto o tempo de um minuto e meio para ler o caso e escrever o diagnóstico.

Para o caso de pneumonia viral, observou-se uma relação inversa entre a acurácia e o esforço mental. Em outras palavras: quanto menos esforço o aluno fez para diagnosticar esse caso maior foi a chance de acertar. Tal fato pode estar relacionado à baixa complexidade do diagnóstico, com requisição do sistema de raciocínio intuitivo e de alto desempenho na maior parte dos casos rotineiros ${ }^{1}$. Outra possibilidade a ser aventada é o viés de disponibilidade (tendência a enxergar mais frequentemente um diagnóstico quando se trabalha mais com quadros clínicos semelhantes), visto que este era o último da sequência de casos, sendo sempre precedido pelos casos de pneumonia bacteriana e com derrame ${ }^{28}$.

A literatura científica atual é divergente 
em predizer taxas de acerto esperadas para o diagnóstico correto por estudantes de medicina em diferentes períodos de graduação ${ }^{29,30}$. Devido a dinamicidade da aquisição de experiência durante a graduação, espera-se que os alunos desenvolvam seu padrão individual de acurácia, sendo esta progressão avaliada de forma oficial (por testes de progresso ou alcance de pontuação mínima para concluir a disciplina) ao término de cada semestre. Pouco se sabe sobre como esta progressão do padrão individual é automensurada, se existe consistência entre estudantes, ou se eles gerenciam as incertezas em torno dos limites de ação adequadamente. A baixa taxa de acerto encontrada neste estudo, mesmo para casos simples, pode estar relacionada à amostragem com alunos em fase inicial de atendimento prático, com baixa integração entre aspectos teóricos e apresentação clínica da doença, além de pouco estímulo à metacognição, como autopercepção sobre o conhecimento prévio e auto-eficácia. Nesta etapa, as estruturas cognitivas descritas como "redes causais", com explicações biológicas e fisiopatológicas sobre causas e consequências das doenças, estão em consolidação, com consequente desenvolvimento da habilidade de avaliar as manifestações clínicas de um caso específico de maneira mais integrada e relacionada a grupos de doenças ${ }^{1}$. A condução do estudo nessa etapa de formação, enquanto os alunos ainda não amadureceram a formação dos modelos mentais de doença, associada a fragmentação do conteúdo em várias disciplinas não correlatas, pode ter impactado nos baixos níveis de acurácia diagnóstica encontrados.

Um possível viés do estudo seria o fato de que alguns estudantes cursaram Pneumo- logia como matéria optativa durante a graduação. No entanto, na análise estatística, esta variável não mostrou relação com maiores níveis de acurácia, menor percepção de esforço mental ou maior percepção de conhecimento prévio. Uma explicação possível para esse fato seria o número amostral pequeno; outra seria o fato dos casos clínicos abordarem pacientes pediátricos com patologia aguda e a disciplina optativa de pneumologia ser voltada para atendimento e discussão de patologias respiratórias crônicas em adultos.

Este estudo apresenta algumas limitações. A auto-eficácia, reconhecidamente associada a acurácia diagnóstica, não foi avaliada. O termo auto-eficácia refere-se à crença e confiança que um indivíduo tem na sua capacidade de realizar com sucesso as tarefas que lhe são atribuídas ${ }^{31}$. Espera-se que indivíduos com alto nível de auto-eficácia, quando confrontados com um desafio, assumam uma postura ativa para equacioná-lo, acreditando no sucesso do seu desempenho. Por outro lado, sujeitos com baixo nível de auto-eficácia tendem a se frustrar e desistir da solução do problema $^{32}$. Segundo um estudo realizado na Universidade de Medicina da Turquia, níveis mais altos de auto-eficácia (o mais forte preditor individual de desempenho acadêmico) estão correlacionados com o uso de níveis mais elevados de estratégia de aprendizagem ${ }^{17}$.

A validade externa do estudo tem limitações relacionadas à amostra - estudantes de quarto ano de uma faculdade de medicina privada com currículo tradicional. Existe necessidade de estudos que avaliem essas variáveis em estudantes de períodos posteriores ou de faculdades que utilizem 
modelos alternativos de currículo (como o problem based learning - PBL) para avaliar se existe impacto destes fatores na acurácia diagnóstica e na percepção de esforço mental para a resolução de casos clínicos. Existem várias evidências experimentais que mostram que o desenvolvimento do raciocínio clínico e a acurácia diagnóstica estão intimamente relacionados ao estágio de aprendizagem teórico-prático em que se encontra o aluno da graduação ${ }^{33,34}$.

Não existe modelo de raciocínio clínico ou fator associado ao aprendizado que, de forma isolada, possam explicar como e por que estudantes de sucesso chegam ao diagnóstico correto, enquanto estudantes mal sucedidos não. Não é simplesmente o conhecimento que resolve casos clínicos, mas sim a aplicação consciente deste conhecimento em etapas ordenadas e direcionadas a um objetivo - a solução do caso ${ }^{35,36}$. Se os alunos tiverem uma representação clara de uma patologia em relação à sua clínica predefinida, noção do conhecimento do que eles sabem e como integrar sintomas e achados clínicos, então eles têm uma chance muito boa de diagnosticar corretamente o paciente ${ }^{37}$.

\section{CONCLUSÃO}

Neste estudo, no qual foi avaliada a relação entre a percepção de conhecimento, o esforço mental e a acurácia durante resolução de casos de pneumonia, ocorreu uma associação significativa entre o conhecimento prévio e o esforço mental, embora essa relação não tenha necessariamente determinado maior acurácia diagnóstica. Ao relacionar estas variáveis, foi possível avaliar importantes características do aprendizado de estudantes de medicina, que auxiliarão no desenvolvimento de estratégias de ensino que favoreçam maior acurácia com menor esforço mental. Os achados deste estudo mostraram que é preciso estimular pesquisas que estudem fatores associados ao aprendizado, a fim de aprimorar os processos envolvidos na mobilização de recursos cognitivos para realização de diagnósticos corretos, que qualificarão o ensino médico.

\section{REFERÊNCIAS}

1. Peixoto JM, Santos SME, De Faria RMD. Processos de desenvolvimento do raciocínio clínico em estudantes de medicina. Rev Bras Ed Med. 2018; 42(1):73-81.

2. Rodrigues GV, Machado LC. Raciocínio clínico, uma sistematização seria pertinente. Rev Med Minas Gerais. $2015 ; 26: 1-5$

3. Thomas EJ, Studdert DM, Newhouse JO, Zbar BI, Howard $\mathrm{KM}$, Willians EJ, et al. Costs of medical injuries in Utah and Colorado. Inquiry 1999; 36:255-264.

4. Schwanda-Burger S, Mochh H, Muntwyler J, Salomon $F$. Diagnostic errors in the new millennium: a follow-up autopsy study. Mod Pathol. 2012; 25:777-783.

5. Mamede S, van Gog T, van den Berge K, Rikers RMJP, van Saase JLCM, van Guldener C, et al. Effect of availability bias and reflective reasoning on diagnostic accuracy among internal medicine residents. JAMA. 2010, 304:1198-1203.

6. Melo M, Gusso GDF, Levites M, Amaro Jr. E, Massad E, Lotufo PA, et al. How doctors diagnose diseases and prescribe treatments: an fMRI study of diagnostic salience. Sci Rep. 2017; 7:1-11.

7. Philip $\mathrm{AH}$. Regulating accuracy on university tests with the plurality option. Learn Instr. 2013; 24: 26-36.

8. Norman GR. Research in clinical reasoning: past history and current trends. Med Educ. 2005; 39:418-427. 
9. Coderre S, Mandin H, Harasym PH, Fick GH. Diagnostic reasoning strategies and diagnostic success. Med Educ. 2003; 37(8):695-703.

10. Charlin B, Boshuizen HPA, Custers EJ, Feltovich PJ. Scripts and clinical reasoning. Med Educ. 2007; 41:11781184.

11. Schmidt HG, Norman GR, Boshuizen HPA. A cognitive perspective on medical expertise: theory and implication. Acad Med. 1990; 65:611-621.

12. Schmidt HG, Rikers RMJP. How expertise develops in medicine: knowledge encapsulation and illness script formation. Med Educ. 2007; 41:1133-1139.

13. Dunlosky J, Thiede, KW. Four cornerstones of calibration research: Why understanding students' judgments can improve their achievement. Learn Instr. 2013; 24:58-61.

14. de Bruin ABH, Van Gog T. Improving self-monitoring and self-regulation: From cognitive psychology to the classroom. Learn Instr. 2012; 22(4):245-252.

15. Mamede S, Van Gog T, Van den Berge K, Rikers RMJP, Van Saase J LCM, Van Guldener C, Schmidt HG. Effect of availability bias and reflective reasoning on diagnostic accuracy among internal medicine residents. JAMA. 2010; 304:1198-1203.

16. Ibiapina C, Mamede S, Moura A, Elói-Santos S, van Gog T. Effects of free, cued and modelled reflection on medical students' diagnostic competence. Med Educ. 2014:48:796-805.

17. Atalay KD, Can GF, Erdem SR, Müderrisoglu IH. Assessment of mental workload and academic motivation in medical students. J Pak Med Assoc. 2016; 66:574-578.

18. Jolliffe IT. Principal Component Analysis, Series: Springer Series in Statistics, 2ed. New York: Springer; 2002,

19. Fernandes RAF, Ibiapina CDC, Timóteo APP, Malloy-Diniz LF. Dinâmica de desenvolvimento do raciocínio clínico e da competência diagnóstica na formação médica - sistemas 1 e 2 de raciocínio clínico. Rev Med Minas Gerais. 2016; 26(6):15-18

20. Young JQ, van Djik SM, O'Sullivan PS, Custers EJ, Irby $\mathrm{DM}$, Cate $\mathrm{O}$. Influence of learner knowledge an case complexity on handover accuracy and cognitive load: results from a simulation study. Med Educ. 2016; 50:969-979.

21. Cowles JK, Kubany AJ. Improving the measurement of clinical performing in medical students. J Clin Psychol.1959; 15:39-42.

22. Pulito AR, Donnely MB, Plymale M. Factors in faculty evaluation of medical students' performance. Med Educ. 2007;41:667-675

23. Braun LT, Lenzer B, Kiesewetter J, Fischer MR, Schmidmaier R. How case representations of medical students change during case processing - Results of a qualitative study. GMS J Med Educ. 2018; 35(3):1-15.

24. Mamede S, Schmidt HG, Rikers RMJP, Custers EJFM, Splinter TAW, van Saase JLCM. Conscious thought beats deliberation without attention in diagnostic decision making: at least when you are an expert. Psychol Rev. 2010; 74:586-592
25. Mamede S, Splinter TAW, Van Gog T, Rikers RMJP, Schmidt HG. Exploring the role of salient distracting clinical features in the emergence of diagnostic errors and the mechanisms through which reflection counteracts mistakes. Br Med J. 2012; 21:295-300

26. Krupat E, Wormwood J, Schwartzstein RM, Richards JB. Avoiding premature closure and reaching diagnostic accuracy: some key predictive factors. Med Educ. 2017 51:1127-1137.

27. Woods NN, Howey EHA, Brooks LR, Norman GR. Speed skills ? Speed, accuracy, encapsulations and causal understanding. Med Educ. 2006; 40: 973-979.

28. Croskerry P. The importance of cognitive errors in diagnosis and strategies to minimize them. Acad Med. 2003 78:775-780.

29. Langendyk V. Not knowing what they do not know: self assesment accuracy of third year medical students. Med Educ. 2006, 40:173-179.

30. Mahajan R, Badyal D, Gupta P, Singh, T. Cultivating Lifelong Learning Skills During Graduate Medical Training Indian Pediatr. 2016; 53:797-804.

31. Bandura A. Self-efficacy: toward a unifying theory of behavioral change. Psychol Rev. 1977; 84(2):191-215

32. Barros M, Santos ACB. Por dentro da autoeficácia: um estudo sobre seus fundamentos teóricos, suas fontes e conceitos correlatos. Rev Esp Acad. 2010; 112:1-9.

33. Rikers RMJP, Schmidt HG, Boshuizen HPA. Knowledge encapsulation and the intermediate effect. Contemp Educ Psychol. 2000; 25(2):150-166.

34. Charlin B, Boshuizen HPA, Custers EJ, Feltovich PJ. Scripts and clinical reasoning. Med Educ. 2007; 41:11781184.

35. Demirören M, Turan S, Öztuna D. Medical students self-efficacy in problem-based learning and its relationship with self-regulated learning. Med Educ. 2016; 21:1-9.

36. Anthony R, Artino JR. Academic self-efficacy: from educational theory to instructional practice. Perspect Med Educ. 2012; 1:76-85.

37. Schmidmaier R, Eiber S, Schiller M, Hege I, Holzer M Martin R. Learning the facts in medical school is not enough: which factors predict successful application of procedural knowledge in a laboratory setting? BMC Medic Educ. 2013; 13-28.

\section{CORRESPONDÊNCIA}

Gabriela Araujo Costa

Rua Aristóteles Caldeira, 1010/302

Grajau Belo Horizonte, Minas Gerais Cep 30431-108

E-mail: gabiacl@gmail.com 